This document was prepared in conjunction with work accomplished under Contract No. DE-AC09-96SR18500 with the U.S. Department of Energy.

This work was prepared under an agreement with and funded by the U.S. Government. Neither the U. S. Government or its employees, nor any of its contractors, subcontractors or their employees, makes any express or implied: 1 . warranty or assumes any legal liability for the accuracy, completeness, or for the use or results of such use of any information, product, or process disclosed; or 2 . representation that such use or results of such use would not infringe privately owned rights; or 3 . endorsement or recommendation of any specifically identified commercial product, process, or service. Any views and opinions of authors expressed in this work do not necessarily state or reflect those of the United States Government, or its contractors, or subcontractors. 


\title{
HYDROGEN EFFECTS ON THE BURST PROPERTIES OF TYPE 304L STAINLESS STEEL FLAWED VESSELS
}

\author{
Michael J. Morgan, Monica Hall, Poh-Sang Lam and W. Dean Thompson, \\ Savannah River National Laboratory, Aiken, SC 29808-0001
}

\section{ABSTRACT}

The effect of hydrogen on the burst properties Type 304L stainless steel vessels was investigated. The purpose of the study was to compare the burst properties of hydrogen-exposed stainless steel vessels burst with different media: water, helium gas, or deuterium gas. A second purpose of the tests was to provide data for the development of a predictive finite-element model. The burst tests were conducted on hydrogen-exposed and unexposed axially-flawed cylindrical vessels. The results indicate that samples burst pneumatically had lower volume ductility than those tested hydraulically. Deuterium gas tests had slightly lower ductility than helium gas tests. Burst pressures were not affected by burst media. Hydrogen-charged samples had lower volume ductility and slightly higher burst pressures than uncharged samples. Samples burst with deuterium gas fractured by quasi-cleavage near the inside wall. The results of the tests were used to improve a previously developed predictive finite-element model. The results show that predicting burst behavior requires as a material input the effect of hydrogen on the plastic strain to fracture from tensile tests. The burst test model shows that a reduction in the plastic strain to fracture of the material will result in lower volume ductility without a reduction in burst pressure which is in agreement with the burst results.

\section{INTRODUCTION}

The burst test is commonly used throughout industry to evaluate pressure vessel designs. At the Savannah River Site (SRS), burst tests are used to evaluate the properties of stainless steel vessels used for the long-term storage of hydrogen isotopes. Burst tests are used to verify overall vessel integrity, evaluate material performance and demonstrate that particular designs are compatible with the long-term effects of hydrogen and tritium gas. Tritium gas service is of particular concern to SRS because tritium and its decay, product helium3 , can accumulate within the vessel walls and change the structural properties of the steels (1-4). The changes in burst properties (pressure and ductility) depend on overall reservoir shape, size, and exposure history and are not understood.

There is growing interest in developing predictive finiteelement models that capture the long-term effects of hydrogen and tritium gas on the structural properties of pressure vessels.
While both hydraulic and pneumatic tests have been conducted on vessels taken out of service, pneumatic burst testing with deuterium gas may be required in the future as a more conservative approach for evaluating the long term tritium effects. Because, pneumatic tests release so much more strain energy that hydraulic tests, a program was set up to evaluate the facilities and instrumentation that would be needed for conducting the pneumatic burst tests. As part of that program, a study was conducted to determine the effects of burst media on burst properties.

The purpose of this study was to compare the burst properties of vessels burst hydraulically with those burst pneumatically with either helium or deuterium gas. A second purpose was to provide material data for developing better analytical tools for predicting burst behavior.

\section{EXPERIMENTAL PROCEDURE}

Twelve sample vessels, approximately 0.80 " diameter and 3" long were fabricated from Type 304L pipe grade stainless steel. The test specimens are prototypical and are not vessels in production. Each of the vessels was electric-discharge machined with an axial notch at a depth of $20 \%$ of the wall thickness as depicted in Fig. 1. Un-notched samples will be tested at later date.

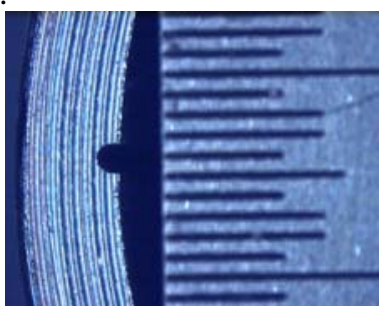

Figure 1. Typical Depth and Geometry of Notch Machined on Inside Wall Prior to Burst Test

The vessels were burst in the Savannah River National Laboratory High Pressure Laboratory (HPL). A stainless steel "plug" was inserted into each vessel to reduce the volume and minimize the strain energy released during the tests. Four vessels were burst using water as the pressurization fluid, four using deuterium gas, and the final four with helium gas. Six of the vessels were hydrogen charged prior to bursting, that is, they were uniformly saturated with hydrogen at $623 \mathrm{~K}$ and 34.5 
MPa. The hydrogen content was estimated using the charging conditions and the parameters of San Marchi, et al. (5). The concentration of hydrogen in the walls of the charged cylinders was calculated to be 3730 appm.

On all burst tests performed, the volume growth was measured by submerging the vessel in a bucket of water that was suspended from a balance. The balance measured the volume displacement of the water as the vessel deformed which directly corresponds to the amount of volume growth of the vessel. Two cameras were set up in the HPL walk-in gun barrel to record the bursts. Fig. 2 shows a schematic of the test set-up, and Fig. 3 shows a photograph of the set-up.

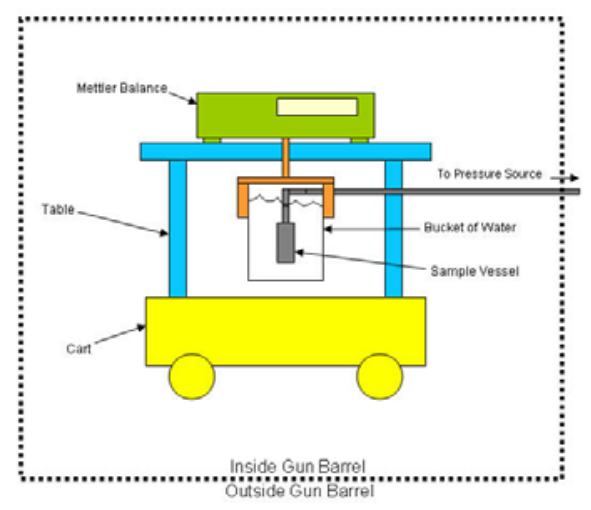

Figure 2. Schematic of Test Set-up

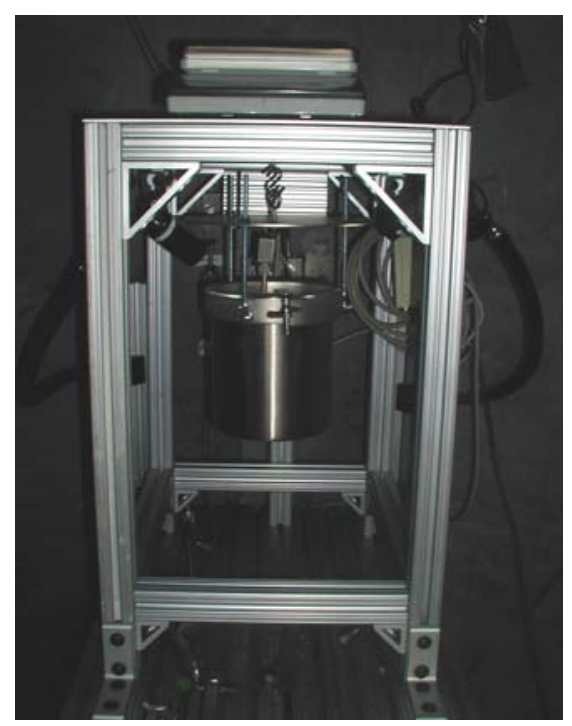

Figure 3. Set-up for Burst Testing in High Pressure Laboratory.

\section{RESULTS}

Figure 4 shows the typical records from the burst tests. The results show that the shape of the pressure vs. volume change behavior was independent of the burst media but that the point of failure was different for each of the media. Vessels burst hydraulically tended to have a greater volume change before failure than those burst pneumatically.

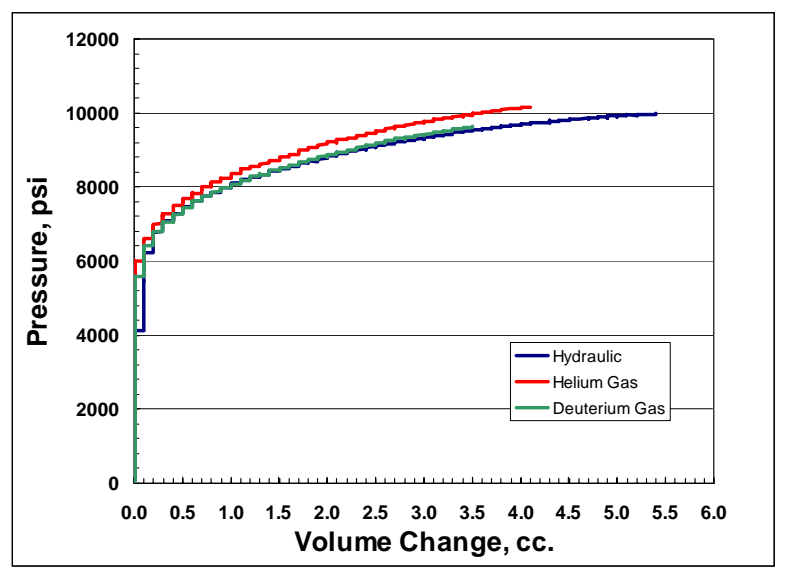

Figure 4. Typical Pressure-Volume Change Record for Burst Tests of Type 304L Cylinders.

Figure 5 shows a new vessel, a hydraulically burst vessel, and a pneumatically burst vessel. The burst test resulted in fracture initiating at the machined notch and running along the length of the vessel. For the vessels burst hydraulically, the length of the crack after burst was about $1 / 3$ the length of the vessel. For the vessels burst pneumatically, the crack ran the full length of the vessel and even began to unwrap at the cap weld because of the much larger strain energy released.

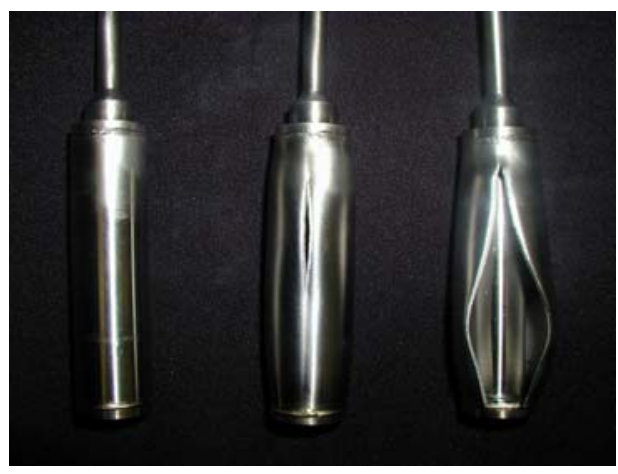

Figure 5. Burst Test Sample From Left to Right: New, Hydroburst, Deuterium Burst

Figure 6 shows a comparison of the various tests and their burst pressures. Note that all samples failed with a burst pressure of about $69 \mathrm{MPa}$. Hydrogen-charged samples tended to fail with a slightly higher burst pressure. This occurs because of the large amount of hydrogen that was pre-charged into these samples (3730 appm). The yield strength of the steels is increased by this quantity of hydrogen which resulted in the slight increase in the burst pressure. 


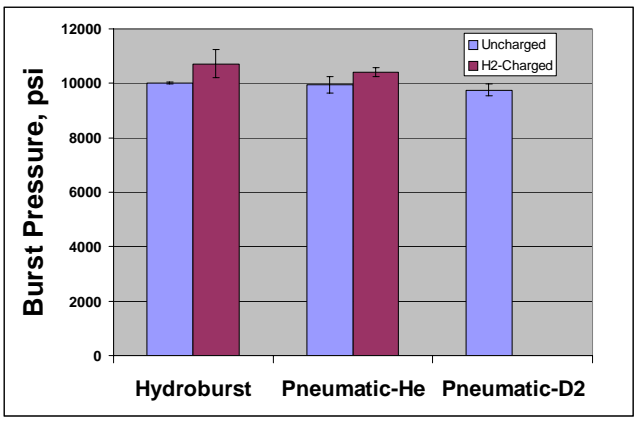

Figure 6. Burst Pressure Was Unaffected by Burst Media. Hydrogen-charged Vessels Had Higher Burst Pressure than Uncharged Vessels.

Figure 7 shows the results of the volume change during the burst tests. Samples burst pneumatically had lower percent volume ductility than those tested hydraulically. Deuterium gas tests had slightly lower percent volume than helium gas tests. Hydrogen-charged samples had lower percent volume (Figure 5). The results are summarized in Table I.

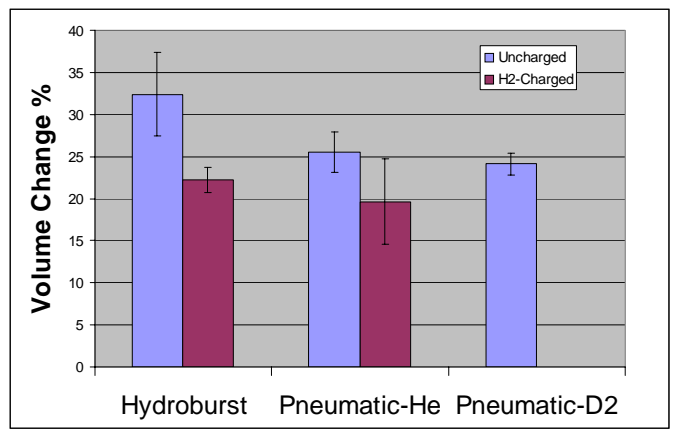

Figure 7. Percent Volume Change for Hydrogen-Charged and Uncharged Vessels Burst with Different Media.

Table I Burst Pressures and Volume Growth

\begin{tabular}{|c|c|c|c|c|}
\hline Bottle SN & Burst Type & $\begin{array}{c}\text { Hydrogen } \\
\text { Charge? }\end{array}$ & $\begin{array}{c}\text { Burst } \\
\text { Pressure, } \\
\text { psi }\end{array}$ & $\begin{array}{c}\text { Volume } \\
\text { Growth, } \\
\text { Cc }\end{array}$ \\
\hline 1 & Hydroburst & No & 10040 & 4.3 \\
\hline 6 & Hydroburst & No & 9985 & 5.4 \\
\hline 7 & Pneumatic - He & No & 10158 & 4.1 \\
\hline 9 & Pneumatic - He & No & 9743 & 3.6 \\
\hline 5 & Pneumatic - D2 & No & 9902 & 3.8 \\
\hline 10 & Pneumatic - D2 & No & 9607 & 3.5 \\
\hline 8 & Hydroburst & Yes & 11089 & 3.5 \\
\hline 11 & Hydroburst & Yes & 10356 & 3.2 \\
\hline 3 & Pneumatic - He & Yes & 10287 & 2.4 \\
\hline 12 & Pneumatic - He & Yes & 10519 & 3.5 \\
\hline 2 & Pneumatic - D2 & Yes & & \\
\hline 4 & Pneumatic - D2 & Yes & & \\
\hline
\end{tabular}

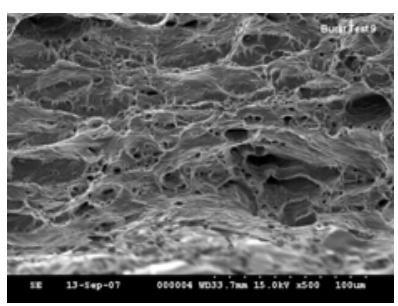

Inner Surface

(Dimpled Rupture)

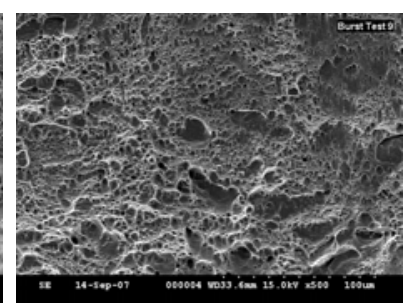

Outer Surface

(Dimpled Rupture)
Figure 8. Fracture Appearance of Cylinders Burst Hydraulically

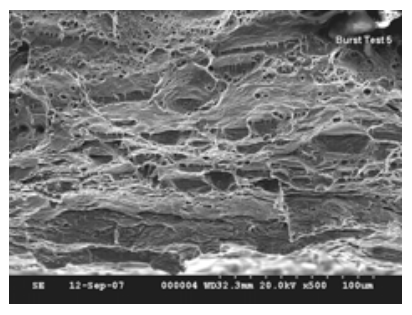

Inner Surface

(Quasi-Cleavage)

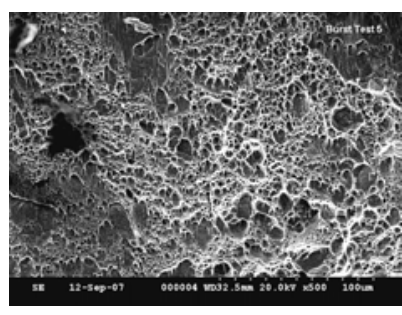

Outer Surface
Figure 9. Fracture Appearance of Cylinders Burst With Hydrogen Gas

The burst sample fracture surfaces were examined to characterize the fracture modes. All samples tended to have two distinct fracture regions: inner wall and outer wall. Notice in Figure 8 the distinct difference in the fracture appearance between the inner and outer wall. Samples burst hydraulically and pneumatically with helium gas tended to fail by the dimpled rupture process, i.e., microvoid nucleation, growth and coalescence. The microvoids on the fracture surface of the inner region tended to be larger than those in the outer region.

Figure 9 shows the fracture appearance of one of the cylinders burst with deuterium gas. Notice that the fracture mode of the inner region was not dimpled rupture but quasicleavage. Quasi-cleavage is a fracture mode that is typically seen in stainless steel tensile bars fractured in the presence of hydrogen gas (6). Thus, bursting with deuterium gas changed the volume ductility and the fracture mode.

\section{DISCUSSION}

The results of this study show that burst media will affect the burst properties of stainless steel vessel. While burst pressure showed little change with burst media (Fig. 6), burst ductility, as measured by the change in volume during the burst test, is affected by burst media (Fig. 7). Hydrogen pre-charging caused a slight increase in burst pressure and a decrease in burst ductility. Vessels burst with deuterium gas had lower volume ductility than those burst hydraulically. Furthermore the volume ductility change was most likely caused by a deuterium effect on fracture mode (Fig. 9). The fracture mode 
of the vessels burst with deuterium gas failed by quasi-cleavage which was different than the dimpled rupture fracture modes observed in the vessels burst hydraulically.

A materials system model and finite element procedure were developed in a earlier study (7) to predict burst pressure and the vessel volume change (ductility) during burst testing. The model was used to predict changes in burst pressure and ductility from the hydrogen or tritium service history, known values of hydrogen isotope diffusivity, and published data on the effects of hydrogen, tritium, and helium on the tensile properties of stainless steel.

Good agreement was achieved with actual burst test data for unexposed vessels in the earlier study. It was shown that the service history could be used to derive values of tritium concentration in the metal and the depth of penetration in the vessel sidewall. These values could be used in the finite element model to predict values of burst pressure and burst ductility for tritium-exposed vessels.

In the tests of this study, hydrogen pre-charging and deuterium gas pressurization lowered the volume ductility of burst-tested vessels (Fig. 7). This is similar to the ductility changes caused by material in tritium service. The ductility of the tritium-aged material is significantly reduced as a result of helium-3 precipitated in the microstructure of the metal due to tritium decay, in addition to the effect of hydrogen (tritium) embrittlement.

Better analytical tools for predicting the effects of hydrogen, tritium, and decay helium because burst testing for tritium-exposed vessels is very difficult and costly because of challenges associated with the large energy released from deuterium pressurization as well as the tritium off-gas and contamination control. As a result, it is desirable that an analytical/numerical technique be developed to complement, or even provide an alternative to, the burst testing. The method should be capable of predicting the burst pressure, and more importantly, the volume ductility which is a measurement of the change in volume of the vessel at burst failure.

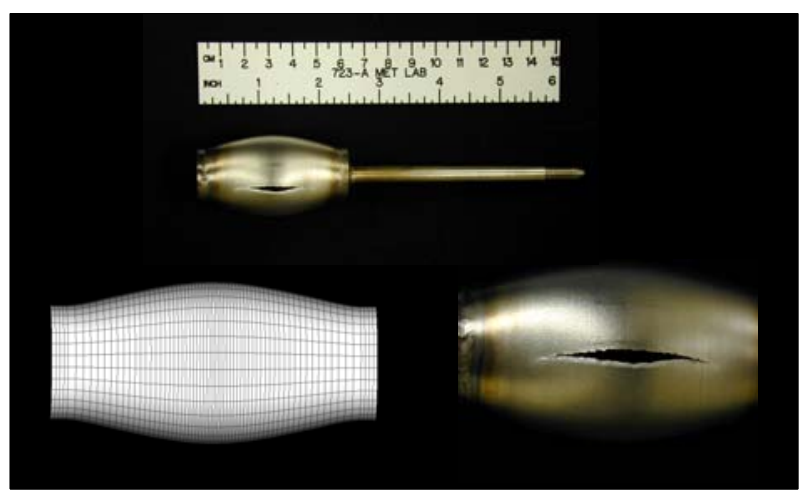

Figure 10. Burst Cylindrical Vessel and Finite-Element Model Showing Agreement Between Deformed Shapes (7).
The finite element procedure developed in the present work has demonstrated that the burst pressure and volume ductility can be predicted for unexposed vessels (Fig. 10). However, for the vessels that have been in hydrogen or tritium service, only qualitatively consistent results can be reported at this time, that is, the burst pressures remain similar but the ductility is significantly reduced as the exposure time increases. A strong dependence of volume ductility on the hydrogen isotope and helium concentration is expected. For example, when a uniform distribution of helium with 100 APPM penetrating $20 \%$ of the vessel inside wall, the volume ductility is predicted to be just $1 / 3$ of that for a helium-free material (Fig. 11).

Note that in Figure 12, taken from our earlier work (7), that hydrogen or tritium induced changes in the maximum plastic strain to fracture are predicted to cause a change in volume ductility measured in a burst test. At the same time, the model predicts little change in burst pressure for the same change in the plastic strain to fracture. This is entirely consistent with the results observed in these experiments on Type 304L stainless steel (Figs. 6 and 7).

The hydrogen isotope and helium concentration profiles are functions of the initial condition, duration of aging, and the off-gas temperature, etc., the detailed fabrication information and service history are essential to create a realistic finite element model with an appropriate material idealization for accurate prediction of the burst properties. A systematic approach with a carefully selected test matrix, and a complete material property database should be developed.

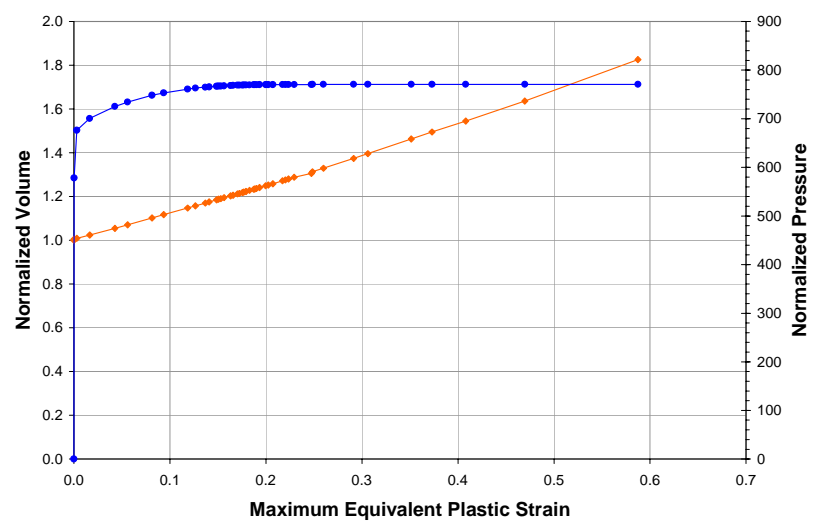

Figure 11. Expected Volume Change (Red Curve) and Expected Burst Pressure Change (Blue Curve) with Changes in the Maximum Equivalent Plastic Strain to Fracture (7).

\section{CONCLUSIONS}

1. Cylinders burst tested pneumatically had similar burst pressures but lower volume ductility than those tested hydraulically. Burst pressure is not significantly affected by burst media. 
2. Samples burst with deuterium gas had lower ductility and different fracture modes than those tested hydraulically.

3. Hydrogen-charged samples had lower ductility and slightly higher burst pressures than uncharged samples

4. Finite-element modeling can qualitatively predict the expected changes in burst properties with hydrogen or tritium service, but a better material property database is required for quantitative predictions.

\section{ACKNOWLEDGMENTS}

The authors wish to acknowledge the support from the U. S. Department of Energy (DOE) to the Savannah River National Laboratory (SRNL) under Contract No. DE-AC09-96SR18500.

\section{REFERENCES}

[1] Robinson, S. L., 1990, "The Effects of Tritium on the Flow and Fracture of Austenitic Stainless Steels", in Hydrogen Effects on Material Behavior, ed. A. W. Thompson and N. R. Moody, The Minerals, Metals \& Materials Society, pp. 433445.

[2] Robinson, S. L., 1987, "Tritium and Helium Effects on Plastic Deformation in AISI 316 Stainless Steel," Materials Science and Engineering, vol. 96, pp. 7-16.

[3] Morgan, M. J., 1990, "The Effects of Hydrogen Isotopes and Helium on the Flow and Fracture Properties of 21-6-9 Stainless Steel,” Proc. Fine Symposium, ed. P. K. Liaw, J.R. Weertman, H. L. Marcus, and J. S. Santner, Warrendale, PA., TMS, pp. 105-111.

[4] Louthan, Jr., M. R., 2001, “Tritium Decay, Irradiation and Hydrogen/Helium Effects on Type 316L Austenitic Stainless Steel,” WSRC-MS-2001-00040, Westinghouse Savannah River Company, Aiken, South Carolina.

[5] C. San Marchi, B.P. Somerday and S.L. Robinson, "Permeability, Solubility and Diffusivity of Hydrogen Isotopes in Stainless Steels at High Gas Pressures”, International Journal of Hydrogen Energy, Volume 32, Issue 1, January 2007, 100116.

[6] G. R. Caskey, Jr., "Hydrogen Effects in Stainless Steels", Hydrogen Degradation of Ferrous Alloys, ed. J. P. Hirth, R. W. Oriani, and M. Smialowski, eds., (Park Ridge, NJ: Noyes Publication, 1985), p. 822.

[7] P. S. Lam, M. J. Morgan, K. J. Imrich, and G. K. Chapman, "Predicting Tritium and Decay Helium Effects on Burst Properties of Pressure Vessels" Proceedings of PVP2006ICPVT-11 2006 ASME Pressure Vessels and Piping Conference, July 23-27, 2006, Vancouver, BC, Canada. 